\title{
Sarmiento y Hernández: Divergencia y Conciliación
}

Todavía juegan arduamente en el ir y venir de nuestro país las condiciones polares de esa antinomia. Sarmiento sintetizó así, en Conflictos y armonias..., el advenimiento a la fórmula falaz y reiterativa:

El pensamiento argentino, más reposado y reflexivo a medida que se alejaba del teatro del combate diario y abandonando las recriminaciones inútiles, se lanzó por vías hasta entonces inexploradas y llamó a la cuestión de Civilización y Barbarie, que despertó las simpatías de raza, de cultura y de humanidad de todos los corazones, poniendo en la picota de la exectación universal, el terror y las inauditas crueldades de que se habían hecho un sistema los bárbaros apoderados del gobierno.

En esta mirada hacia atrás, el ojo de Sarmiento no se engaña a sí mismo. El aparato positivista funcionará, como veremos, con relativa acuidad y transferirá al plano de aparente cientificismo éste y otros principios más o menos efectivos, pero en el fondo la ambigüedad subsiste. Subsiste sobre todo si abanidonamos la simplicidad con que el liberalismo redujo el problema a síntesis diametral para redondear sin rebabas el pensamiento del ensayista genial.

Pero el acondicionamiento maniqueísta de la realidad originado en Hegel a través de la versión insuficiente de Herder, o más allá, sigue haciendo correr tinta a críticos avezados o ingenuos. Ricardo Rojas vio claro que Sarmiento logró, por lo menos, desplazar hacia lo social el emblema político, con la cual -y esto tho lo vio Rojas-- Sarmiento se halló, además, en la conjugación totalizadora que hizo del gran tema un nudo de ingredientes muy incitadores pero el alucinado observador de una realidad y un tiempo, de otro modo inasibles. Lo político por sí solo había resultado panfleto, libelo ensangrentado y feroz; lo narrativo, cuadro costumbrista a la Figarillo; lo programático, lección moral o pedagógica. 
La nueva fórmula lo desligaba de frenos y le permitía romper todos los moldes con impunidad, sin renunciar a su férula ni a su entusiasmo creador.

Pero si esta nota debe ser algo más que el intento de reseñar intenciones y logros en el Facundo, hay que enumerar posibles puntos de conexión con Hernández y otras facetas del propio Sarmiento. Y no es que intente una síntesis como conciliación de contratios, a lo Hegel, cosa que ni el mismo Sarmiento quiso sostener porque era amigo de oposiciones restallantes y porque el país, en su juicio, no tenía nada que ganar con ella por entonces. Se trata, pues, ya que la materia lo permite, de confrontar dos individualidades poderosas, reconstruir el mapa donde jugaron su acción, de calibrar sus ideas con toda la sutileza posible, de sorprenderlos en sus rasgos de carácter, en la debilidad o vigor de su pensamiento, en el modo de apuntar al futuro, en la humildad o arrogancia de su escritura, en la validez actual de su mensaje.

Algunos conceptos - vigentes unos, otros ya caducos- sirven $\mathrm{d} e$ apoyo inicial. Esos conceptos juegan a veces como parejas de opuestos: sumisión-revolución, independencia-esclavitud o libertad, opresión-insurrección, república-monarquía, ilustración-ignorancia, ideas todas que en el avanzar del siglo se suman a contenidos políticos (unitarios-federales) y a su expresión socializada y étnica: civilización-barbarie, o a su cristalización mediatizada: pampa-ciudad.

Sin duda se había avanzado mucho en cuanto al espectro de posibilidades especulativas. Monteagudo resumía así, en El Censor de la Revolución (10 de julio, 1820) y en forma de polaridad evidente, los progresos logrados contra el acondicionamiento anterior: "Humilla el recordar la estrecha esfera de nuestras necesidades intelectuales, antes de la época en que hemos llegado: la más urgente de todas, que es conocer el destino del hombre en la sociedad, apenas existía entre nosotros". Después de enumerar "los principios que tienen conexión con la ciencia del gobierno, las verdades abstractas de la filosofía y sus aplicaciones prácticas... el carácter de las relaciones humanas que unen a los individuos del género humano...", agrega Monteagudo que en cuanto a necesidades físicas teníamos lo que puede hacer la felicidad de "los salvajes que habitan nuestros desiertos meridionales...". Monteagudo es optimista: nada tiene que ver esa lucha de la revolución con Ios "salvajes" - -ya veremos que lo mismo estima Sarmiento- y que el país se ha erguido en espléndida condición vertical desde el "día que parecimos hombres por la primera vez".

El resplandor iluminista de Monteagudo no se ha apagado al llegar 
a Sarmiento. Pero algo ha pasado, y muy brevemente lo expone el autor de Facundo en sus últimos años de gobierno:

La revolución de la independencia la hicicron los hijos educados de los españoles ricos. Era un movimiento del cerebro, preparado por las luces que se filtraban por entre las barreras... Los liberales, pues, los patriotas... son lo que llamaríamos la aristocracia americana, las familias cultas y ricas.

Sarmiento apunta también a los rasgos estéticos de esa oligarquía fundadora: "Los primeros militares de los ejércitos pertenecen a la clase más elevada y se distinguen por la belleza de las formas, en general blancos". El sintagma contiene elementos denunciadores de algo más, como se ve. Sarmiento estanca los compartimentos, Ios hace incomunicables. La escala sufre, sin embargo, perturbaciones que conducen a la quiebra del equilibrio étnico-social. Lo expone así :

Al descender el movimiento hacia el grado subsiguiente, el comercio, las artes, la agricultura, el pastorero, de la costa al interior, de las ciudades a las campañas, de la raza europea a la indígena, el movimiento empezó a retardarse, acabando por suscitar resistencias; y con el andar del tiempo, triunfando la resistencia, la fuerza de inercia, el paganismo, el antiguo espíritu colonial. Este hecho de mecánica social -continúa el maestro- bastaría a explicar nuestras revoluciones.

Se ve que el texto es del 80, años "spencerianos" por excelencia, años de escépticos y naturalistas, años en que el "virus" inmigratorio que el propio Sarmiento alimentó hasta la obsesión, producía el horror del mestizaje que terminaría con la dignidad de la raza blanca en esta parte del continente o en todo el mundo americano. Porque Sarmiento extiende su mirada a la América indigena, ve que la indiferencia del "vecindario" en el orden municipal se debe sin duda a la "incorporación de los indígenas", como ve que "los cholos son una raza bastarda intermediaria que produce, como lo observa Agassiz, degeneraciones morales tanto como físicas".

"Los indios son nuestros padres prehistóricos a quienes hemos detenido en sus peregrinaciones e interrumpido en su marcha", piensa el antropólogo Sarmiento. Pide respeto para su memoria, exhorta a no olvidar que "son la primera página de la historia del hombre", del mismo modo que se reconocerá "gaucho civilizado", capaz "de extraerle al 
caballo la última gota de marcha" cuando Rocinante (véase su artículo "La conciencia castellana, XLV, 288) lo tome como gringo. Es la "gringada que ni siquiera/se sabe atracar a un pingo", de Hernández, la imagen que se nos enfrenta inconscientemente.

También en ese dominio del inconsciente debió yacer el cuadro alucinante de las indiadas de San Gregorio, cuando Hemández, en una feroz embestida contra Mitre condena en él haber integrado con aborigenes sus ejércitos siempre en fracaso:

Rosas tuvo indios en Caseros; y apenas tronó alli el cañón que debía poner término a su tiranía, los indios se dispersaron... El último Rosas - se refiere a Pedro Rosas y Belgrano, ahijado suyoque conservaba en el sur un resto de prestigio, penetró en la Provincia de Buenos Aires en 1852, trayendo en sus filas los indios que se encontraron en la batalla de San Gregorio. Se dispersaron como en Caseros, después de inútiles cargas dadas en medio de salvajes alaridos, y desde la costa del Salado hasta sus tolderías... no hicieron sino saquear cuanto hallaron, incendiar poblaciones, asesinar a los vecinos, cautivar mujeres y niños.

Guillermo E. Hudson tiene algo parecido en Allá lejos... como espectador que fue de esa batalla. Pero Hernández — de ahí el inconsciente de represión- participó en ella como soldado. Fue su bautismo de fuego... con los indios, peleando en el mismo pelotón... Nos preguntamos: ¿su odio contra el aborigen se originó allí? Los Huarpes de Guanacache le inspiran a Sarmiento aquel hermoso capítulo de Recuerdos de Provinciat. Algo como la nostalgia de un paraíso perdido se filtra entre líneas. En el Martin Fierro, bien lejos de lo elegíaco, el odio y la repugnancia babean náusea y hortor en el texto:

\footnotetext{
Allá no hay misericordia

ni esperanza que tener;

el indio es de parecer

que siempre matarse debe

pues la sangre que no bebe

le gusta verla correr
}

$(I, \quad \vee .229-234)$

Mientras Sarmiento subraya la pasividad, la inercia del indio como ingrediente de degradación en su mestizaje con el blanco, Hernández 
sostiene con permanente furor la imagen pavorosa y animal del indio que "odia a muerte al cristiano" con su "instinto de crueldá", con su gravedad impasible y sin sontisa, con su "alarido atroz" y sus nombres "de animales y fieras".

Estos enjuiciamientos provienen de la $_{\text {a }}$ Pimera parte, aunque, como se sabe, aparecen multiplicados en la Segunda. Pero estamos ya en 1879, la dispersión a balazos del indio amenaza con su exterminio y Hernández (¿Sarmiento?) experimenta alivio ante el triunfo que él mismo ha saludado desde las columnas de El Río de la Plata.

Estas cosas y otras piores

las he visto muchos años;

pero, si yo no me engaño

concluyó ese bandalaje,

y esos bárbaros salvajes

no poidrán hacer más daño"

(II, v.667.672)

A su propia gente verá dispersarse y sucumbir. Por ahora festeja, por cierto con mezcla de pavor y amarga satisfacción, el holocausto de una raza:

Las tribus están desechas;

los caciques más altivos

están muertos o cautivos

privaos de toda esperanza

y de la chusma de lanza

ya muy pocos quedan vivos.

$$
\text { (II, v.673-678) }
$$

Es un reconocimiento a través del cual cruza un tufo de infernal horror; algo semejante al que deja traslucir Sarmiento en la muerte precipitada y sin respiro de Facundo Quiroga.

José Mármol ya había construido, a lo Byron, su "Salvaje de la pampa que vomitó el infierno", y en sus Cantos, el aborigen había engendrado como en la llanura a ese "gaucho salvaje de la pampa ruda". Con más gracia y naturalmente con una simpatía que es común en la simbolización neoclásica del hombre americano, Hidalgo dejaba para su fama esta certeza de virtud poética, en uno de sus "Cielitos": 


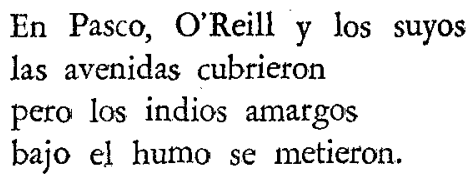

Amaro Villanueva llama a esto - cosa de indios que no lo son étnicamente- "retruque subversivo", para comentar luego cuando tropieza con aquello de:
Cielo, cielito que sí
guárdese su chocolate:
aquí somos puros indios
y sólo tomamos mate.

"El solo hecho de oponer dos costumbres indigenas americanas -el chocolate y el mate- como manifestaciones opuestas de civilización y barbarie, revelan --agrega Villanueva-, el acto reflexivo con que el poeta tradujo al verso la plenitud de su intención". (Crítica y pico. Santa Fe, 1945, pp. 191-192).

Si seguimos el hilo con que Sarmiento se mueve dentro de la madeja inextricable de nuestras turbulencias iniciales nos encontramos, así, como descubrimos la intervención forzada y negativa del indio en el matidaje racial, la no menos fatal y destructora de los blancos alzados, de los rebeldes contra la propia dignidad de sangre:

Todos los jefes de montonera (de amontonarse, de ganar el monte) fueron calaveras criollos de la clase blanca... Todos aquellos hijos de familias españolas amontonados, todos aquellos grandes y mínimos out-laws o desertores de los ejércitos, se apoderaron de las ciudades, ya con un ejército de línea... o con gentes rústicas descendientes de los indios mitayos o reducidos y aún de paisanos criollos o de estirpe mezclada que obedecían siempre porque esa exa la tradición de la frontera, al llamado de los capitanes de frontera" (T. XXXVIII, 276/7).

El trozo es significativo: va desde lo textual -lo claro y directoa lo sugerido y emblemático. La frontera es la línea que separa dos campos, dos territorios; pero también la que aísla el nivel de lo lícito, lo angélico, de lo prohibido y condenable. Es también la frontera de Her. nández y la de Fenimore Cooper... 
Revisado el proceso de conformación racial después de cuarenta años, se ve que en Sarmiento persisten los mismos prejuicios conceptuales, agravados ahora por el aparato pseudo-científico del positivismo digerido apresuradamente. $\mathrm{Y}$ se ve, releyendo ese fragmento de Conflicto y armonia, que esas "gentes rústicas descendientes de los indios mitayos" no son otros que los "bastardos" y los gauchos, "los paisanos criollos o de estirpe mezclada". Son los de sangre de que no aborrarse, según el consejo transmitido a Mitre desde la silla de gobierno. José Manuel Estrada, desde una óptica distinta, coincide con Hernández en la estimación de lo justo y lo afirmativo cuando dice que:

No hay justicia en la campaña. No puede haberla por cuanto los que tienen necesidad de ella están obligados a buscarla en el sagrado Olimpo que termina en las barrancas de Santa Lucía y se trueca insensiblemente en Averno a través de las gradaciones graciosas del bienestar que se cambia en infortunio, simbolizadas en los Jardines de San José de Flores.

El texto es irónico y constituye, al duplicar también las zonas intransferibles, una versión no menos infernal que la dicotómica de Hernández y de Sarmiento, aunque de hecho, más cargada de humanidad. Lo sensible es también, si se lee con cuidado, que mientras para Hernández lo demoníaco es lo indígena, para Sarmiento lo "crudo" es todo lo que separa la incontaminada blancura, de lo oscuro y mestizo: el indio pero también el gaucho. El otro enemigo de Sarmiento - Juan Bautista Alberdi- no superó tampoco esa antinomia. El autor de las Bases sugería una experiencid, naturalmente dentro de la medicina de Claudio Bernard: "Haced pasar del roto, el gaucho, el cbolo, unidad elemental de nuestras masas populares, por todas las transformaciones del mejor sistema de instrucciớn; en cien años no haréis de él un obrero inglés". Claro que en el mismo texto se le opone a Sarmiento y sus métodos "persuasivos": "La grandeza de creación en lugar de la grandeza salvaje de exterminio". (O. C., T. VIII). El esquema es el que Estrada estigmatiza:

. . criar una sociedad civilizada superpuesta a la otra: la sociedad privilegiada, monopolista, peninsular, urbana, sobre la sociedad nativa, productora, rural. ...Esta es la clave de numerosos y horrendos desastres en el azaroso curso de la revolución patria" (en "Una palabra suprimida: la campaña"). 
Los límites de lo humano y lo bestial (sangre blanca, dignidad, dinamismo industrioso, espiritualidad y equilibrio moral contra todo lo que lo niega) se observa en todos los grados de estas propuestas sarmentinas y hernandianas. La crítica ha observado con frecuencia la aplicación de la tesis lombrosiana que asimila estructuras craneanas, pilosidad, etc. a la condición humana o animal del bípedo hombre ... o gaucho-indígena. John B. Hughes lo vio bien cuando analiza el pasaje de Hernández en los versos 1315-1320 de la Vuelta: "En el indio -señala Hughesaún los pormenores de su agonía mortal son de indole animal y no sólo animal sino "inclasificable" para el hombre "civilizado". Por eso "le salían de la garganta como una especie de aullidos" (en Arte y sentido del Martín Fierro, p. 137). Facundo, el "otro tigre", el de los llanos, es en Sarmiento lo mismo. El indio es lo irredimible: "No esperen verlo cambiar", aconseja José Hernández. Claro es - hay que anticiparloque el texto sarmientino no es simplemente derecho y revés, blanco y negro. Su ambigüedad, lo que lo hace literatio, es decir complejo, casi inasible, hondo, lo que aún desvela a la crítica y la envuelve en incertidumbre irreparable, es lo otro: una adhesión incondicional e incondicionada a eso que precisamente niega, a lo que con palabras de Kush puede llamarse "seducción de la barbarie" y que es el mismo factor que creó sus juegos antinómicos, el mismo estímulo que obró en todos los románticos desde Chateaubriand a Byron y Víctor Hugo. Lo de Hernández difiere, y no porque la ambivalencia sea menos visible sino porque mientras vio en el indio la forma simplemente primaria y animal, miró al gaucho como lo que se yergue contra lo supuestamente negativo en el aborigen, como quien debe terminar con él, como el "civilizador" de la pampa, lo mismo que Lugones. De ahí la constante apelación a las autoridades cuyo paternalismo no alcanza para "amparar", para "proteger" al gaucho. $Y$ señalo esos verbos porque menudean con sugestiva elocuencia en todo el texto del Martín Fierro: "sin más amparo que el cielo", "ni amigo ni protetores", no tengo donde ampararme", "si no tiene una mujer/que lo ampare y lo consuele". Bl mismo Sarmiento queda implícito en la escritura de Hernández por alusiones bien claras: "Todo se güelven proyectos/de colonias y carriles/y tirar la plata a miles/en los gringos enganchaos"; "El campo es del inorante/el pueblo del hombre estruido"; "Me voy - le dije- ande quiera/aunque me agarre el gobierno/pues infierno por infierno/prefiero el de la frontera".

Las oposiciones afectan aquí a los criterios de progreso, de avance técnico $\mathrm{y}$, desde luego, a la imagen del hombre culto, tan diferente en uno y otro. Sarmiento identifica ciudad con cultura y civilización; niega que ella exista fueta de los hacinamientos urbanos, y su inquietud no le 
da tiempo para ver, como Lugones, las formas que la esclavitud asume para la "chusma" (?!) de la ciudad, sometida y torpe, a la condición del gaucho libre y dueño de su destino. Hernández proponía otras pautas, por lo menos hasta su retorno al seno de la ciudad ya acogedora del 80 . El Martin Fierro muestra la indole contrastante de ambas posiciones ("Aquí no valen dotores/ sólo vale la esperencia") mientras la condición de "varonía" no es la del pueblero sino la del hombre en soledad, poderoso de músculo y voluntad de resistencia, sabio de intuiciones naturales, aunque todos los calificativos del puebleto sirvan para justificar el atropello y el exterminio:

Si uno aguanta es gaucho bruto;

si no aguanta es gaucho malo.

Déle azote, déle palo

porque es lo que él necesita!

De todo el que nació gaucho

esta es la suerte maldita.

$$
\text { (I, v.1372-1378) }
$$

"De eso se trata", protestaba Sarmiento: "De ser o no ser salvaje". Denunciaba el epíteto con que se acompañaba la presencia del unitario para él -aunque no lo fuera- signo de avance por lo menos mental contra la supuesta barbarie rosista. El mismo Hernández se mostraba adherido a aquellos determinantes políticos cuando al iniciar en 1863 su Vida del Chacbo, como en un contra-Facundo, escribía:

Los salvajes unitarios están de fiesta. Celebran en estos momentos la muerte de uno de los caudillos más prestigiosos, más generoso y más valiente que ha tenido la República Argentina. El Partido Federal tiene un nuevo mártir.

Algunos pasajes aluden claramente al Facundo escrito "sin más objeto que deprimir un partido que no podían vencer y haciéndose remunerar con largueza por los suyos, ese trabajo". Otros pasajes, también como en Sarmiento poseído por el momento político de 1845, se refieren a la urgencia con que el panfleto es abordado y las consecuentes faltas de información e ilación que el lector puede observar. Habrá que esperar hasta 1874 para encontrar un Hernández polemista de semejante talla, cuando sus resentimientos políticos lo lancen con increíble violencia contra el general Mitre. Por ahora está en el campo en el que se encuen- 
tra también Olegario Andrade, el autor de Las dos politicas, folleto en algún tiempo atribuido al propio Hernández. Allí se lee: "Así se levantó Ramírez! Así se han levantado todos los caudillos en defensa de un principio sagrado, de una idea generosa!".

La guerra del Paraguay, iniciada un año después, lo encontratá, naturalmente, también en el campo contrario, donde militan todos los hombres de Paraná y con ellos su gran amigo el poeta Guido Spano. Hernández se pregunta en nombre de qué principios el país se atreve a intervenir en un país vecino; habla de la "repulsión" que provoca semejante actitud y se pregunta:

¿Cómo puede llamarse guerra de regeneración para el Paraguay la que estamos sustentando, arrebatando palmo a palmo el territorio $y$ pasando adelante sobre los cadáveres de los defensores?

Por entonces cunde la amenaza contra su diario. Sarmiento lo hostiga secretamente y. Hernández responde sin inmutarse:

Más sirve a los gobiernos la prensa opositora que la prensa oficial... Ia exageración de la oposición en la prensa se destruye por sí misma... Los que combaten la libertad de prensa, los que desconocen hay los preceptos del derecho y de la justicia, se exponen a ser mañana las víctimas de su injustificada aberración.

El enfrentamiento reitera la eterna polémica de campaña y vida urbana. Hernández habla de Buenos Aires, que "se resiente todavía de los privilegios monstruosos del coloniaje". "Aquí - agrega lo mismo que Estrada- se ha creado una especie de aristoctacia, a la que paga tributo la campaña desamparada, como los vasallos del señorío feudal". Por momentos nos hallamos en un nivel de aproximaciones que niegan, en el fondo, las disidencias más visibles. Para Hernández - tratemos de hilat fino- Ia revolución política de Mayo no termina con lo pernicioso de aquel sistema colonial. Para Sarmiento la barbarie es la forma que asume la resistencia a abandonar los módulos coloniales y los hábitos culturales y de convivencia. "La ciudad era pues invulnetable", insiste Hernández. El tema desplaza la atención hacia la relación pueblo-gobierno:

Los gobiernos despóticos que surgieron de la anarquía y de las convulsiones sociales, concibieron entonces una idea satánica: No podemos imponernos al pueblo, se dijeron con diabólica sontisa, pero podemos fraccionar ese pueblo y levantar una fracción contra 
la otra... La dictadura de Rosas cumplió ese plan y sabemos cuál fue su resultado.

El razonamiento lo ha llevado quizá demasiado lejos. También pudo decir: despotismo rivadaviano, centralista o como se llame, y despotismo rosista o federal, lo mismo da. Pero le interesa agotar su argumento, ir a la médula de su enfrentamiento:

¿Qué importa -se pregunta - que tengamos exposiciones, telégrafos, ferrocarriles, si los indios nos invaden, si la vida peligra, - si la propiedad está amenazada en todo momento? No podrá pensar el viajero que los gobiernos que han debido resolver ese problema de la seguridad individual en la campaña, han empezado por quebrantar sus derechos e imponerles la esclavitud del servicio individual, como si no fueta lo mismo para los ciudadanos, ser víctimas de los indios o serlo de los gobiernos?

Hernández ve a fondo. Si cotejamos aquellas ideas de Sarmiento acerca de una revolución hecha por la artistocracia y éstas de Hernández, advertimos otra fase de los desencuentros que padecen. Escribe Hernández:

Incapaces de remontarse hasta los grandes principios de la democracia, husmearon posiciones eminentes y la gran fragua electoral se hacía desde el ministerio del que aspiraba a la presidencia, después de haber derrotado a su rival en su mismo gabinete. (En La Oligarquía, del 20 de noviembre de 1869).

$\mathrm{La}$ ironía suele entibiar o acidular la agresividad de sus argumentos. Hernández no reniega de la cultura, y la suya no es tan improvisada como se ha pretendido. Pero odia el acortonamiento y la apariencia de planificar la alfabetización que cree descubrir en el nuevo presidente, como odia las embestidas guerreras de Mitre, a quien considera nulo de estrategia política y militar. "Esto se llama ir de mal en peor --escribió un día en La Capital de Rosario". "Con Mitre ha tenido que andar la República con el sable a la cintura. Con Sarmiento va a verse obligada a aprender de memoria la Anagnosia, el método gradual y los anales de Dña. Juana Manso".

Pero la actualidad del 73 y el 74 lo hallan en desbandada con las fuerzas de nuevo insurgentes, de López Jordán, hasta que asienta sus reales en Montevideo, siempre con una plana de diario por llenar, su 
pan de cada día, lo mismo que en su enemigo. La Patria, de su amigo Soto, se le abre para que arroje desde ella los dicterios más feroces que registran los anales de nuestro periodismo. El "maquiavelismo" de Mitre se lo impone, el general que "halaga su fantasía y su vanidad con sueños de fama póstuma, de haber sido el primer soldado americano". La pre. sidencia de Mitre asumió para él este perfii:

Fueton tres años de devastación, de incendio, de sangre, en que todo fue arrancado de su quicio, en que la República se vio estremecida por los más sangrientos horrores, los suplicios más crueles y las vejaciones más inauditas, mientras que el sombrio, el tétrico autor de tanto incendio, se entregaba indolente, en la populosa Buenos Aires, en brazos de una vida de verdadero sibarita.

$Y$ agrega:

A un pueblo viril se le martiriza, se le sacrifica, se le degüella como lo hizo don Bartolo con las provincias y Sarmiento con la de Entre Ríos, pero no se arranca de su conciencia el sentimiento de su libertad y el culto de sus derechos... Es el último de los grandes malvados.

Como se ve, le ha tocado a Hernández el asumir frente a Mitre la misma actitud de Sarmiento frente a Rosas y. casi con el mismo lenguaje.

Sarmiento aparecerá luego - en 1875- ya tranquilo por primera vez, bajo el gobierno de Avellaneda - como "un caro hijo de la República". Será cuando suscite de nuevo la burla de Sarmiento al editar, ahora sin el prólogo, su Vida del Cbacbo. Pero su turbulencia se aquieta al fin y la Vuelta de Martín Fierro registra el paulatino desplazamiento hacia el campo donde inevitablemente se encuentran sus enemigos de antes. Una dedicatoria de su posma al general Mitre, previo recuerdo de haberlo combatido durante veinticinco años, una banca de senador y el reconocimiento de que la campaña no es ya un ultraje al gaucho sino un campo de experimentación rural, lo vuelven otro. El discurso en defensa de la federalización de Buenos Aires contra la tesis sustentada por su viejo amigo Leandro N. Alem, prueba que ha aprendido mucho, que sabe manejar en términos de técnica actualizada los conceptos sobre economía nacional e internacional, la azarosa instalación de capitales extranjeros, el fomento de la inmigración, la política de granos y el funcionamiento de los puertos. No quiere ahora que se permanezca en los viejos esquemas políticos, que se siga hablando de unitarios y federales. Habla 
de Buenos Aires, sin cuyo poder "el gobierno del señor Sarmiento no hubiera tal vez alcanzado la terminación de su período legal" y de Mitre a quien "le ha alcanzado la gloria en vida". Se alegra de que ya se cerrara el período de los caudillos "que extendían su poder hasta donde alcanzaban a clavar su lanza" y da un voto por las instituciones del país "porque ellos han de hacer la felicidad (del pueblo) y han de asegurar su porvenir". Y también desliza un cierto temor por los avances imperialistas: "El pueblo inglés, el centro monetario de Londres, tiene hipotecado a su favor una gran parte del orbe".

La imagen del hombre que surge de estas tres exposiciones no se aparta de la normalidad dominante. Esa imagen es paralela a la que surge de Intstrucción del estanciero, de 1882 "... .un pequeño curso de moral administrativa para el uso de los comandantes militares, comisarios pagadores y cuantos tienen que hacer con el pobre gaucho". Es el juicio, para mí visiblemente irónico, con que Navatro Viola da entrada al libro en su Anuario.

Hernández cierra su exposición que consigue la federalización de Buenos Aires con palabras que pudieron ser de su enemigo de antes:

La paz y un buen régimen administrativo han de hacer que muy pronto llamen la atención de los capitales y de la industria, des. envolviendo la prosperidad de la Provincia... Alentemos a las empresas, no trabemos la iniciativa individual, no llevemos la acción oficial más allá de su misión... y veremos cómo las fuerzas vigorosas de la Provincia se desenvuelven con increíble rapidez. Nuestras tiquezas naturales fluyen por todas partes, llamando la atención de las capitales que buscan empleo lucrativo...

Hernández ha hecho, como el personaje de Carpentier, su peregrinación a las fuentes. La Vuelta es un retorno. Martín Fierro permanecerá en esa zona más allá de cuyos límites el hombre se parece inexorable. mente a la humanidad de que forma parte. La escritura de Hernández lo contiene implícito en su mundo que sigue siendo, por lo menos, la mitad del nuestro. La lectura nos reingresa a su totalidad.

Guillermo ArA 
